\title{
Teacher Professional Development Coupons for Thai English Teachers: An Implementation Fidelity Study
}

\author{
Sirikanya Srichom* Denchai Prabjandee Punwalai Kewara \\ Faculty of Education, Burapha University, Thailand
}

\begin{abstract}
Despite the Ministry of Education in Thailand has supported Thai English teachers to attend several teacher professional development programs, few attempts have been made to find out whether the teachers are able to apply what they gained from the teacher professional development programs into their classrooms. This study attempts to fill this gap by studying an implementation fidelity of Thai English teachers who enrolled the teacher professional development coupons project. A variety of data was elicited for a semester academic year consisting of interviews, classroom observations, and teacher's journal to determine the extent the teachers implemented the knowledge gained from the TPD. The data revealed that the participants selectively implemented the appropriated activities. Even teachers enrolled the same TPD programs, however they did not show the same phenomenon. It depends on teacher needs, background of teachers, background of students, school context, and time available. Suggestions for implementation fidelity of the TPD program was pivotal both during the process to confirm that the TPD program has presented as it was designed and follow up after the TPD program to explore how participants implemented the new knowledge into their classroom.

Keywords: Teacher professional development, professional development, follow up, Implementation fidelity, Implementation

DOI: 10.7176/JEP/10-24-09

Publication date: August 31st 2019

\section{Introduction}

This paper reports the phenomenon of in-service Thai English teachers who enrolled in the teacher professional development programs implemented the new knowledge in the classrooms. These teachers were provided a budget to participated teacher professional development (TPD) programs based on their interests, after the TPD programs, I conducted an implementation fidelity study to explore how and why teachers applied new knowledge in their classrooms.

Several countries around the world have provided various professional development for their teachers (European Commission 2009, p.48; Eurydice 2008, pp. 47-53) hence teacher professional development is an important element for successful teaching career. Like other countries, Thailand has provided various professional development programs for teachers including Thai English teacher professional development programs.

It is important to note that those programs did not fully succeed. Prior literature revealed that after the professional development, most teachers were not able to transfer the knowledge and skills from the professional development into their classrooms (Borko 2004, Potcharapanpong 2010, p.39). It was pointed that the prior TPD had no follow up or any support after the professional development programs were implemented. The result got along with Noom-ura (2013, p.146) who studied English-teaching problems and Thai teachers' professional development needs. She recommended for any TPD program that is well established, it is worthwhile to conduct a follow-up study to find out whether the participants are henceforth able to solve their teaching problems or apply what they gain from the program in their teaching situation.
\end{abstract}

\subsection{Teacher professional development coupons}

Professional development programs in this study were under the OBEC training project, launched by the Ministry of Education, Thailand. It is the national policy project in which allowed educational institutions: school and university, government service: educational service area office, provincial education office, and corporate: company, partnership, association, and foundation to present their teacher professional development's curriculum to Teacher Professional Development Institute (TPDI) store. The TPDI considered the quality of the offered curriculums with 15 criteria, then announced the proved curriculums. In-service teachers were offered ten thousand baht each to attend the approved professional development programs based on their interest. All the approved programs called as the professional development program or teacher professional coupons.

\subsection{Implementation fidelity}

The concept of following up after TPD is called "implementation fidelity". Carroll et al. (2007) defined it as the degree to which an intervention or program is delivered as intended. The previous studies shown the positive effects of implementation fidelity on early childhood teacher/classroom outcomes. In addition, implementation fidelity study revealed the teachers partly implemented classroom language in English after they were provided 
the Content and Language Integrated Learning (CLIL) approach (Kewara and Prabjandee, 2018, p.93). The reasons hidden why or why not implemented were interesting to explore in order to produce the effective professional development in the future.

Previous studies have applied different frameworks based on the goal of the studies to measure the implementation fidelity. For example, five-dimensions approach: adherence, exposure, quality of program, participant responsiveness, and program different (Dane \& Schneider 1998), critical components: the programs need to be measured to determine whether a program is present or not (Bauman Stein \& Ireys, 1991; Ruiz-Primo 2005; Wang et al. 1984), structure and process approach (Mowbray et al. 2003, Wang et al. 1984), and combining frameworks approach (Lynch \& O’Donnell 2005; Ruiz-Primo 2005). These studies implied that implementation fidelity is multidimensional and need to measure from variety dimensions.

After reviewing and integrating the literature, implementation fidelity in this study can be viewed as the 5 components. I reordered the five dimensions of fidelity and applied some words but still the same meaning based on Dane and Schneider (1998) for measuring implementation fidelity of teacher as APPLE framework or implementation fidelity framework represented to A: Adherence to intervention, $\mathbf{P}$ : Participant responsiveness, $\mathbf{P}$ : Program unique, L: Lively of delivery, and E: Exposure or dosage as display as Figure 1:

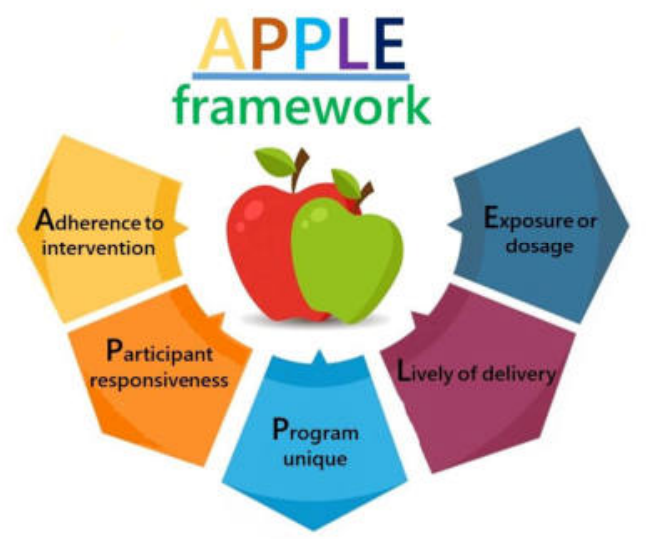

Figure1: APPLE framework of implementation fidelity

\section{The study}

This study was an interpretive qualitative study (Merriam 2002). I was interested in understanding how participants implemented the knowledge gained from the TPD into their classrooms as the phenomenon, the meaning was mediated through the researcher as an instrument. The strategy was inductive, and the outcome was descriptive. The research question was to what extent do the in-service teachers who participated in teacher professional development coupon implemented knowledge from the TPD in their classrooms? To produce a qualitative inquiry that richly descriptive, this methodology guides the methods that supporting researcher to come up with qualitative information to address the phenomenon as follow:

\subsection{Participants}

The purposeful sampling technique was applied to select three participants: Kanlayanee, Porhathai, and Anong who are Thai English teachers in the northeastern part of Thailand. These English teachers participated in the TPD coupon under the OBEC training project. Three of them are volunteer to participate this study and they were allowed from their school director. The participant's characteristic was described as Tablel.

Table 1. The participants' characteristics

\begin{tabular}{|l|c|c|c|c|}
\hline \multicolumn{1}{|c|}{ Name } & Age & Gender & Teaching Experience & TPD \\
\hline Kanlayanee & 47 & Female & 24 & X \\
\hline Porhathai & 33 & Female & 9 & X \\
\hline Anong & 46 & Female & 23 & I \\
\hline
\end{tabular}

As shown in Table 1, all participant is female. Kanlayanee is 47 years old and has taught English for 24 years. Porhathai is the youngest participant: 33 years old and has 9 years experiences in teaching English. Both Kanlayanee and Porhathai enrolled the same TPD program: X program. Anong is 46 years old with 23 years teaching English experiences. She enrolled the I program.

\subsection{Data collection}

The data were used holistically to understand the phenomenon in the classroom on teacher's implementation of 
knowledge gained from the TPD program by classroom observation, interview, and document analysis. The participants were observed while they implemented technique or knowledge gained from the TPD programs in their classrooms. The phenomenon was reported to understand what happened in the classroom observation form: APPLE framework, then transcribed for analysis. Classroom observation was applied until finding the picture of each element saturated. At the end of the observation, participants wrote teacher's diary and used as supplementary data. The purpose of this observation was to examine the extent to which the participants used knowledge gained from the TPD program in their classrooms.

The interviews were recorded and later transcribed for analysis. The aim of interview was to get another perspective implementation fidelity and to reach the maximize of trustworthiness data.

\subsection{Data analysis}

To analyze the data, transcribing the data from classroom observation, interview, and teacher's journal were implemented, determining the extent to which the participants implemented based on APPLE framework. The interview data were analyzed by transcribing and searching for themes to understand the reasons why knowledge or technique gained from the TPD programs were implemented or why not, transcribed for analysis.

\subsection{Ethical considerations}

This study was approved by the Institutional Review Board committee (IRB) and conducted with the permission from the school directors. The author was aware of the participants' right, autonomy, justice, fairness, and independence. The participants were informed the purpose of the study. Participation was voluntary and the participants understood that they had a choice to drop out of the study anytime without any consequences to their jobs. The real names of the participants and also their school's name was not included in this study. Pseudonyms was used instead to protect the participants and their school identity. The name of the professional development program substitute by the English alphabet A-Z in order to protect the professional development coupons.

During data collection process, there was a participant who did not welcome classroom observation. Hence the finding presented here only two participants: Kanlayanee and Porhathai.

\section{Findings}

Kanlayanee and Porhathai participated in the same TPD program: the X program. An outstanding feature of this program is the presentation of open-ended problem into classroom in order to encourage students' thinking skills. Beside the dominant of teaching process, the curriculum has unique management called the Triple-Co. The TripleCo is three collaboratives between teacher and related persons in the school, which included: Collaborative plan, Collaborative do: instruction process and classroom observation, and Collaborative-reflection. Instruction process is a part of Collaborative do which combines with four steps: 1) Presentation of open-ended problem, 2) Students learn by themselves, Discussion and extension of the concept, and 4) Teacher sums up students' concept as display as Figure 2 describes the $\mathrm{X}$ program as follows:

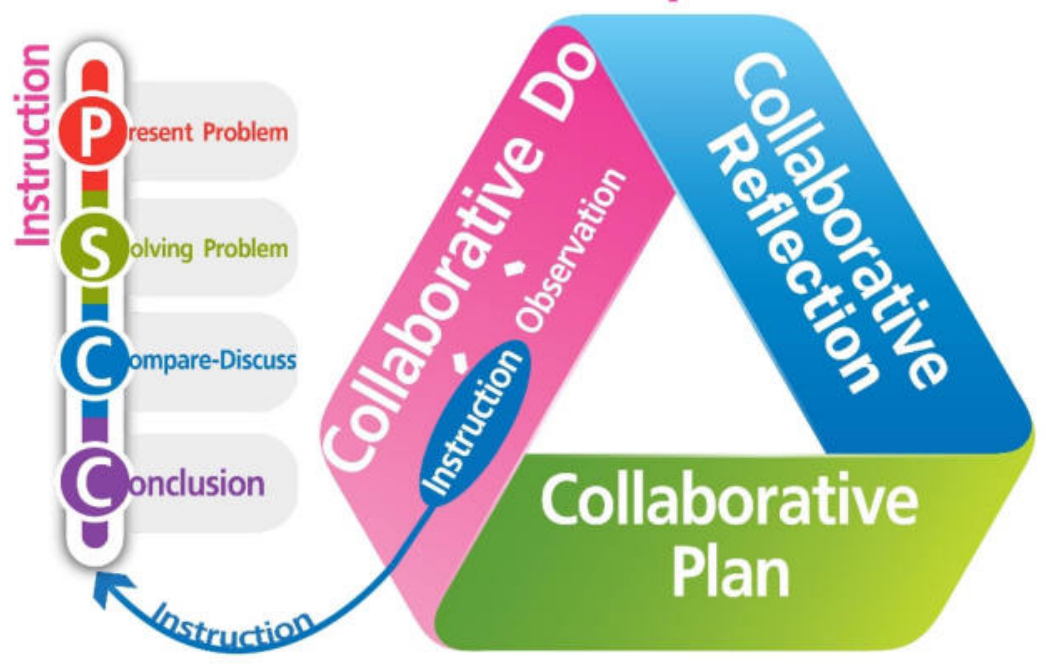

Figure2: Concept of the $\mathbf{X}$ program pedagogy

\subsection{APPLE Framework of Implementation Fidelity in Kanlayanee's Classroom}

Kanlayanee's APPLE framework was glitter each element as follow: Adherence: Kanlayanee has efforts to implement presentation of open ended problem and use English as much as possible in the classroom, Participants 
responsiveness: Kanlayanee's participants have cooperated classroom activities well, obey teacher, and help each other learning, Program unique: Kanlayanee has her own style to present open ended problem by preparing expected answer for the students because she know the students' background knowledge. The classroom activities would not run smoothly without teacher help, Lively of delivery: Kanlayanee is zealous in teaching her students. She is kind even she always speaks loudly. She always prepared her teaching materials well. She has high attempted to encourage her students successfully. She has efforted to implement technique from the TPD into the classroom. Exposure or dosage: Kanlayanee claimed that she implemented the technique gained from the TPD appropriately $66 \%$ a semester.

\subsection{APPLE framework of implementation fidelity in Porhathai's classroom}

Similar to Kanlayanee, Porhathai enrolled in the same TPD program. To discourse specific in-depth detail of classroom events, presenting the details here as APPLE framework as follow: Adherence: Porhathai's adherence covered two parts: instruction process and giving reinforcement. Participants responsiveness: the students have good responsiveness since Porhathai has encourage and elicit. Most of the students have well participated in all classroom activities. However, the students are different, few students are not really collaborated classroom activities. It is natural happened in a big classroom. Program unique: reviewing is outstanding process and program unique of Porhathai, she presented new vocabs, new grammar, and new syntactic structure with other technique beforehand, then Porhathai reviewed vocabs, grammar, or syntactic structure with the presentation of open-ended problem. Lively of delivery: Porhathai's lively of delivery is overwhelming with friendly and supported learning from Porhathai. Porhathai's personality is a kindhearted teacher. Porhathai's teaching circumstances is also encourage the student's learning. Exposure or dosage: Porhathai rarely implemented this approach into the classroom. It is approximately 30\% implementation, regard with the nature of the approach and the content. Porhathai concluded 3 reasons why she rarely implemented this approach into the classroom: 1) Porhathai prefers to use several kinds of leading in for her classroom. 2) Porhathai needs a special room for the English classroom where there is full of teaching materials need for this approach. The students come to study at this room. 3) Porhathai has no time for doing the lesson plan with interested or challenged problem situation and preparing teaching materials.

\subsection{Kanlayanee and Porhathai's APPLE framework}

In this section, I analyzed both Kanlayanee and Porhathai's APPLE framework to explore how they implemented their knowledge in their classrooms. In trying to understand how participants implemented the knowledge gained from the TPD program into the classroom, I synthesized themes founding from the two English teachers, then illustrated with the Venn diagram. The themes included interrelated themes from two English teachers, the unique themes of Kanlayanee and Porhathai. Figure 3 summarizes the themes both English teachers as follows

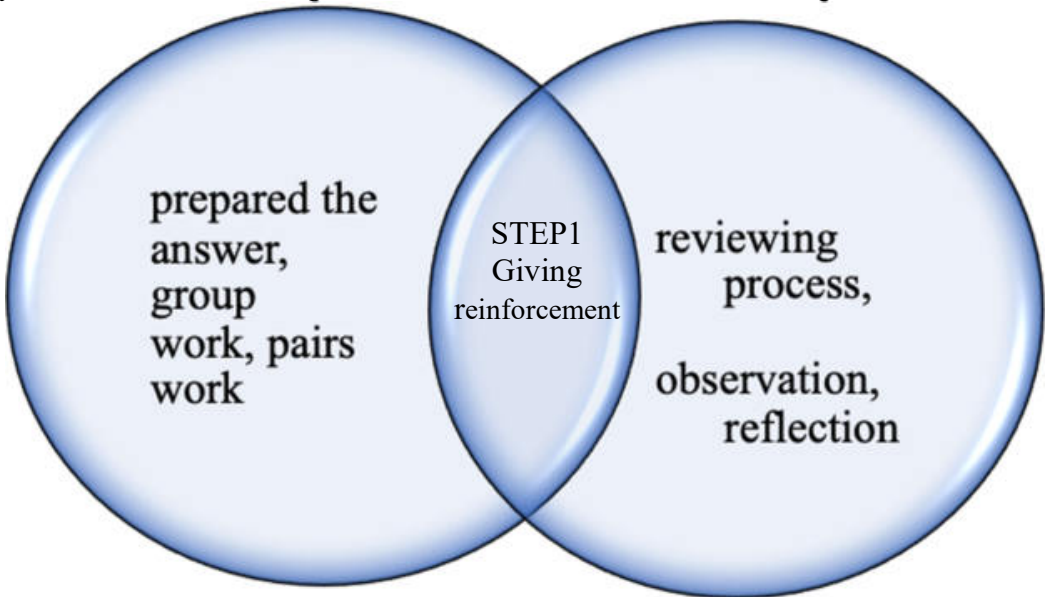

Figure 3: Venn diagram of implementation fidelity

As shown in Figure 3, there were overlapping themes between the two English teachers: STEP1 and Giving reinforcement. There were unique themes that emerged: reviewing process, observation, reflection, prepared the answer, group work, and pair work. Further details were presented the overlapping and the unique themes respectively.

Although Kanlayanee and Porhathai conducted the STEP1: presentation of open-ended problem in their classroom. However, the teachers have definitely different problems to present. The pedagogy of presentation from the TPD program was just set the goal of this step and let the teacher plan appropriate problem to present depend on content/theme what teachers will have the lesson. The teachers have to selectively used techniques in order to 
encourage the students reaching the goal of thinking skill, active learner and get involved all activities. Based on classroom observation, the teachers designed problem or situation, and created the way to present the open-ended problem based on their background knowledge regarding to teaching approach, theme or content, classroom administration and management, and the student's English proficiency.

Even Porhathai and Kanlayanee enrolled the same TPD program, however they have different perspective and need supports differently. The data from classroom observation, interview, and teacher's diary shine the picture of Porhathai and Kanlayanee's perspective against the TPD program which illustrated with Figure 4 as follows:
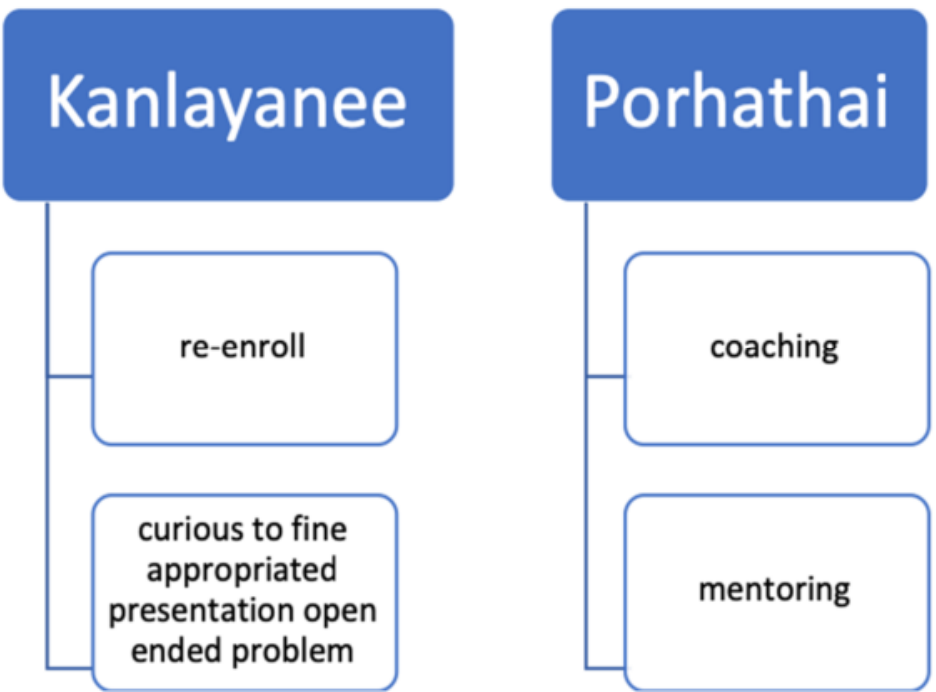

Figure 4: Porhathai and Kanlayanee's perspective against the TPD program

According to Figure 4, Porhathai needs two factors to support and encourage her implemented the knowledge gained from the TPD to the classroom: coaching and mentoring. While, Kanlayanee plans to re-enroll the TPD program again in the next year coming because she still curious to fine appropriated presentation of open-ended problem in English language content.

\section{Conclusion}

In conclusion, by exploring this interpretive qualitative research I have constructed new knowledges 1) implementation fidelity of the TPD program was pivotal both during the process to confirm that the TPD program has presented as it was designed and after the TPD program to follow up how participant implemented the new knowledge into their classroom. 2) The participants are not empty, they have some skills and experiences in teaching. Whenever, they have learned new knowledge, they selected the appropriate way into practice.

To conduct implementation fidelity research, I recommend researchers include measuring implementation fidelity which appropriated with the goal of the research. The researcher choice to select theme or dimensions for example: five dimensions of fidelity: adherence, exposure, quality of delivery, participant responsiveness, and program differentiation (Dan and Schneider, 1998), fidelity in terms of three elements: strength, integrity, and effectiveness of treatment (Yeaton and Sechrest, 1981), three constructs: structure, process, and content (Powell and Diamond, 2013), or study only one and deep dimensions.

Even the participants enrolled the effectiveness professional development coupons but without implemented anything into classroom, it was worse. The changed never happened, hence implementation fidelity is another factor to make it happen.

\section{References}

Borko H 2004, "Professional development and teacher learning: Mapping the terrain", Educational Research, 33(8), 3, https://doi.org/10.3102/0013189X033008003

Carroll C, Patterson M, Wood S, Booth A, Rick J, \& Balain S 2007, “A conceptual framework for implementation fidelity", Implementation Science, doi: 10.1186/1748-5908-2-40.

Dane A, \& Schneider B 1998, "Program integrity in primary and early secondary prevention: Are implementation effects out of control?", Clin Psychol Rev. vol. 18, no.1, pp.23-45.

Kewara P, and Prabjandee D 2018, "CLIT teacher professional development for content teachers in Thailand" Iranian Journal of Language Teaching Research, vol. 6, no. 1, pp. 93-108.

Merriam S B 2009, Introduction to Qualitative Research. San Franciso, CA: Jossy-Bass.

Noom-ura, S 2013, "English-teaching problems in Thailand and Thai teachers' professional development needs" 
English Language Teaching, vol.6, no. 11, pp.139-147, doi:10.5539/elt.v6n11p139

O'Donnell C 2008, "Defining, conceptualizing, and measuring fidelity of implementation and its relationship to outcomes in K-12 curriculum intervention research" Review of Educational Research, vol. 78, no. 1, pp. 3384.

Potcharapanpong S 2010, "TEFL Training program for local and cultural-based instruction: case studies in Thai primary schools", Asian Social Science, vol. 6, no. 9, pp. 39-48, doi:10.5539/a55.v6n9p39

Powell D R, and Diamond K E 2013, "Implementation fidelity of a coaching-based professional development program for improving head start teachers' literacy and language instruction", Journal of Early Intervention, vol. 35 , no. 2, pp. 102-128, doi: $10.1177 / 1053815113516678$

Yeaton W, and Secherst L 1981, "Critical dimensions in the choice and maintenance of successful treatments: strength, integrity, and effectiveness", Journal of Consulting and Clinical Psychology, vol. 49, no. 2, pp. 156167, doi: 10.1037//0022-006X.49.2.156 